\title{
Pioglitazone Lowers Serum Retinol Binding Protein 4 by Suppressing its Expression in Adipose Tissue of Obese Rats
}

\author{
Chaoyu Zhu Yuanyuan Xiao Xiaohua Liu Junfeng Han Jianmei Zhang Li Wei \\ Weiping Jia
}

Department of Endocrinology and Metabolism, Shanghai Jiao Tong University Affiliated Sixth People's Hospital, Shanghai Diabetes Institute, Shanghai Key Laboratory of Diabetes Mellitus, Shanghai Clinical Center for Diabetes, Shanghai, China

\section{Key Words}

Retinol binding protein $4 \cdot$ Pioglitazone $\cdot$ Insulin resistance Adipose tissue

\begin{abstract}
Background/Aims: Pioglitazone, a peroxisome proliferator-activated receptor $\gamma$ activator, is clinically used to treat insulin resistance. However, the underlying mechanism of pioglitazone's action remains unclear. We investigated whether, and how, pioglitazone modulates serum level of retinol binding protein 4 (RBP4), an adipocytokine associated with obesity and insulin resistance. Methods: Insulin sensitivity was determined by oral glucose tolerance test, and RBP4 expression was detected by RT-PCR and Western blotting. Results: Pioglitazone treatment significantly decreased serum RBP4 levels in obese rats, which was correlated with reduced body weight and increased insulin sensitivity. Moreover, pioglitazone greatly decreased RBP4 mRNA and protein levels in adipose tissue but not in the liver. Consistently, pioglitazone treatment significantly reduced RBP4 protein expression in 3T3-L1 adipocytes but not in HepG2 cells. Conclusion: These results demonstrate that pioglitazone inhibits the level of serum RPB4 by suppressing RBP4 expression in adipose tissue of obese rats, suggesting that inhibiting RBP4 expression in adipocytes may provide a mechanism by which pioglitazone improves insulin sensitivity in insulin-resistant subjects.
\end{abstract}

Copyright $\odot 2015$ S. Karger AG, Basel

C. Zhu, Y. Xiao and X. Liu contributed equally to this work.

Li Wei

KARGER 125
Dept Endocrinol Metabol, Shanghai Jiao Tong University Affiliated $6^{\text {th }}$ People's Hospital, Shanghai Diabetes Institute, Shanghai Key Laboratory of Diabetes Mellitus, Shanghai

Clinical Center for Diabetes, 600 Yishan Road, Shanghai 200233 (China)

Tel. +86-18930173636, Fax +86-021-64701361, E-Mail weili63@hotmail.com 


\section{Introduction}

Obesity and its metabolic disorders have been identified as a global health problem, and are strong risk factors for the development of type 2 diabetes mellitus by causing an insulinresistant state in adipose tissue, liver, and muscle. Obesity is defined by abnormal or excessive lipid storage, and is characterized by increasing number and volume of adipocytes. Adipose tissue is not merely a depot for energy storage in the form of triglycerides (TG), but also regarded as a metabolically active endocrine organ which secrets numerous adipokines. The adipose tissue-secreted cytokines modulate inflammation and insulin resistance in diabetic patients [1]. Retinol binding protein 4 (RBP4) is a newly identified cytokine that is primarily secreted by adipocytes and hepatocytes, and is up-regulated during insulin resistance [2, 3]. High circulating RBP4 results in elevated blood glucose by increasing hepatic glucose output and inhibiting insulin signaling in skeletal muscle. An increasing body of evidence from both clinical and experimental studies have corroborated that elevated serum RBP4 level contributes to systemic insulin resistance and is associated with metabolic disorders, including diabetes, dyslipidemia, and cardiovascular risk factors [4-6]. Suppression of serum RBP4 by fenretinide, which increases urinary excretion of RBP4, improves insulin resistance and glucose intolerance $[7,8]$.

Thiazolidinediones (TZDs) is a class of pharmacological agents that ameliorate insulin resistance by enhancing proliferator-activated receptor $\gamma$ (PPAR $\gamma$ ) activity [9]. Activation of PPAR $\gamma$ improves insulin sensitivity by promoting fatty acid storage in adipocytes, inhibiting the production of inflammatory mediators and cytokines, and lowering blood glucose levels $[10,11]$. Several studies have clearly shown that serum level of adipokine RBP4 is significantly down-regulated by TZDs treatment in obese mice and type 2 diabetic patients [12-14]. However, it remains unclear whether adipose tissue and/or the liver mediate suppression of serum RBP4 expression by PPAR $\gamma$ agonists. The aim of the present study was to address this question by examining the regulation of RBP4 in the liver and adipose tissue by pioglitazone, a PPAR $\gamma$ agonist that has anti-diabetic effects.

\section{Materials and Methods}

\section{Animal treatment}

Eight-week-old male Sprague-Dawley (SD) rats $(180-220 \mathrm{~g}, n=24)$ were purchased from Sino-British Sippr/BK Lab Animal Ltd (Shanghai, China). After one week of quarantine (day 0), the rats were randomly assigned to either a standard chow diet group (CON, Slac Laboratory Animal Co. Ltd, China, $3.8 \mathrm{kcal} / \mathrm{g}, 55 \%$ of energy as carbohydrate, $21 \%$ as protein and $24 \%$ as fat) $(n=8)$, or a high fat diet group (HFD, $5.2 \mathrm{kcal} / \mathrm{g}$, $20 \%$ of energy as carbohydrate, $21 \%$ as protein and $59 \%$ as fat $(n=16)$. These diets contain sufficient amounts of vitamin A (20-25 IU/g). After eight weeks on HFD, half of the rats in the HFD group were given pioglitazone (Takada, Japan, dissolved in normal saline [0.9\% NaCl], $20 \mathrm{mg} / \mathrm{kg}$ body weight (b.w.)/day) for four weeks by gavage as HFD pioglitazone-treated (HFD-PT) group, and the other half were given normal saline $(0.9 \% \mathrm{NaCl})$ as HFD un-treated (HFD-UT) group. The chow diet group was also gavaged with saline. The pioglitazone dosage (20 mg/kg b.w./day) was determined as previously reported [15]. All animals had free access to diets and water under a controlled environment $\left(19-22^{\circ} \mathrm{C} ; 30-40 \%\right.$ humidity, and 12 hours light/dark cycle). This study was carried out in accordance with the recommendations in the Guide for the Care and Use of Laboratory Animals of the Shanghai Jiao Tong University. All surgeries were performed under sodium pentobarbital anesthesia and efforts were made to minimize animal suffering.

Insulin tolerance test (ITT)

ITT was performed at the end of pioglitazone or saline treatment by an I.P. injection of insulin (Humulin R, Eli Lilly and Company, USA) at $0.5 \mathrm{U} / \mathrm{kg}$ b.w. after fasting for $4 \mathrm{~h}$. Blood glucose concentration was determined with tail vein blood using a glucometer (Lifescan, Johnson-Johnson Medical (China) Ltd.). The blood glucose levels were measured at 0, 15, 30, 60, 90 and $120 \mathrm{~min}$ after insulin administration. The area under the curves for blood glucose $\left(\mathrm{AUC}_{\mathrm{ITT}}\right)$ was calculated and used to estimate insulin sensitivity. $\mathrm{AUC}_{\mathrm{ITT}}=\left(\mathrm{BG0}^{\prime}+\mathrm{BG} 120^{\prime}\right) / 2+\mathrm{BG} 15^{\prime}+\mathrm{BG} 30^{\prime}+\mathrm{BG} 60^{\prime}+\mathrm{BG} 90^{\prime}$. 
Oral glucose tolerance test (OGTT)

The animals were fasted overnight (12-16 hours) three days after ITT. The rats were given $2 \mathrm{~g} / \mathrm{kg}$ b.w. of glucose through oral gavage. Blood was collected from the retro-orbital-sinus at 0, 30, 60 and $120 \mathrm{~min}$ after glucose challenge, and glucose and insulin levels were measured. The areas under the curves for blood glucose $\left(\mathrm{AUC}_{\mathrm{BG}}\right)$ and insulin $\left(\mathrm{AUC}_{\mathrm{INS}}\right)$ levels were calculated. $\mathrm{AUC}_{\mathrm{BG}}=\left(\mathrm{BGO}^{\prime}+\mathrm{BG} 180^{\prime}\right) / 2+\mathrm{BG}^{\prime} 0^{\prime}+\mathrm{BG}^{\prime} 0^{\prime}+$ $\mathrm{BG}_{120} 0^{\prime}$, and $\mathrm{AUC}_{\mathrm{INS}}=\left(\mathrm{INSO}^{\prime}+\mathrm{INS} 180^{\prime}\right) / 2+\mathrm{INS} 30^{\prime}+\mathrm{INS60} 0^{\prime}+\mathrm{INS} 120^{\prime}$.

\section{Blood biochemistry}

Parameters of serum biochemistry were measured in overnight-fasted rats, including triglyceride, total cholesterol, high density lipoprotein-cholesterol (HDL-C), low density lipoprotein-cholesterol (LDL-C), alanine aminotransferase (ALT), aspartate transaminase (AST), gamma glutamyl transpeptidase (GGT), and plasma glucose. The measurements were performed on a parallel multi-channel analyzer Glamour 2000 (MD Instruments, Muskegon,MI, USA). Serum RBP4 and insulin levels were measured with relevant ELISA kits (Phoenix Biotech, Beijing, China, and Millipore Corporation, Billerica, MA, respectively). The inter-assay coefficient of variation was less than 8 percent for RBP4 and 5 percent for insulin.

\section{Cell culture and differentiation}

3T3-L1 preadipocytes (American Type Culture Collection, Manassas, VA, USA)) were propagated and maintained in DMEM (Gibco, Grand Island, NY, USA) containing 10\% (vol/vol) calf serum [13]. To induce differentiation, 2-day post-confluent preadipocytes at G1 phase (designated as day 0 ) were fed DMEM containing 10\% (vol/vol) fetal bovine serum (FBS, Gibco, Grand Island, NY, USA), $1 \mu \mathrm{g} / \mathrm{ml}$ insulin, $1 \mu \mathrm{M}$ dexamethasone, and $0.5 \mathrm{mM}$ 3-isobutyl-1-methylxanthine (IBMX,Sigma Aldrich, St.Louis, MO, USA) for two days. Cells were then cultured in DMEM supplemented with $10 \%$ FBS and $1 \mu \mathrm{g} / \mathrm{ml}$ insulin for 2 more days, followed by incubation with DMEM containing 10\% FBS. HepG2 cells were cultured in DMEM supplemented with $10 \%$ FBS and $100 \mu \mathrm{g} / \mathrm{ml}$ penicillin/streptomycin (Gibco, Grand Island, NY, USA). 3T3-L1 cells were treated with pioglitazone when over $90 \%$ of the cells had acquired adipose phenotype. Control cells received an equal volume of ethanol. HepG2 cells, at 70-80\% confluence, were similarly treated after a 24-h starvation. Both adipocytes and hepatocytes were treated with pioglitazone at the concentration of 5 , 10 , or $20 \mu \mathrm{M}$, and cells were then collected for the analysis of RBP4 protein expression by Western blotting.

\section{Reverse transcription PCR (RT-PCR)}

Total RNA was isolated from the liver and subcutaneous adipose tissue using TRIzol (Invitrogen, Carlbad, CA, USA), and two $\mu$ g of total RNA were reverse-transcribed into cDNA (Takara, Tokyo, Japan). In each RT-PCR reaction, $2 \mu \mathrm{l}$ of cDNA was amplified in a final volume of $20 \mu \mathrm{l}$ PCR reaction mixture using the TaqMan universal PCR master mix (Takara, Tokyo, Japan). Samples were incubated in the Perkin-Elmer PCR System 9700 (Applied Biosystems, Foster, CA, USA) for an initial denaturation at $95{ }^{\circ} \mathrm{C}$ for $10 \mathrm{~min}$, followed by 35 PCR cycles, with each cycle consisting of $95{ }^{\circ} \mathrm{C}$ for $30 \mathrm{~s}, 62{ }^{\circ} \mathrm{C}$ for $30 \mathrm{~s}$, and $72{ }^{\circ} \mathrm{C}$ for $40 \mathrm{~s}$. The following primers were used: rat RBP4 (accession no. XM_215285.4) 5'- GACAAGGCTCGTTTCTCTGG -3' (sense) and 5' - AAAGGAGGCTACACCCCAGT - $3^{\prime}$ (antisense), and rat $\beta$-actin (accession no. NM_007393.1) 5'CACGATGGAGGGGCCGGACTCATC $-3^{\prime}$ (sense) and 5'- TAAAGACCTCTATGCCAACACAGT - $3^{\prime}$ (antisense). The specificity of the PCR was further verified by subjecting the amplified products to agarose gel electrophoresis based on the expected product size. The mRNA levels of RBP4 and PPAR $\gamma$ were normalized to the internal control $\beta$-actin.

\section{Western blotting}

The liver and adipose tissues were homogenized in lysis buffer (20 mmol/L HEPES, pH 7.5, $150 \mathrm{mmol} / \mathrm{L}$ $\mathrm{NaCl}, 1 \mathrm{mmol} / \mathrm{L}$ EDTA, $1 \%$ Triton X-100, $0.5 \mathrm{mmol} / \mathrm{L} \mathrm{Na}_{3} \mathrm{VO}_{4}$ ) with protease inhibitors (Roche Molecular Biochemicals, Mannheim, Germany). Cultured adipocytes and hepatocytes were lysed in the same lysis buffer, and crude homogenates were centrifuged at $12,000 \mathrm{rpm}$ for $15 \mathrm{~min}$ at $4{ }^{\circ} \mathrm{C}$. Protein concentration was measured by BCA protein quantification Kit (Beyotime, Shanghai, China). Equal amount of proteins were separated on $10 \%$ SDS-PAGE gels, and then transferred onto nitrocellulose membranes (Millipore, Billerica, MA, USA). Membranes were blocked with 5\% non-fat dried milk (NFDM) (Bright dairy, China) in TBST (Tris-buffered saline/Tween-20) for $1 \mathrm{~h}$ at room temperature, and then incubated with anti-RBP4 antibody (Abcam, UK) overnight at $4{ }^{\circ} \mathrm{C}$. After three washes with TBST, 10 minutes each, membranes were 
incubated with HRP-labeled secondary antibody (Sigma, Sigma Aldrich, St.Louis, MO, USA) in 5\% NFDM in TBST for 1 hour at room temperature and washed three times with TBST (10 minutes each). Signals were detected by chemiluminescence using the ECL detection reagent (Millipore, Billerica, MA, USA). The bands were scanned by Image Quant LAS 4000 mini (GE, Fairfield, CT, USA) and quantified by normalizing to the internal control, $\beta$-actin or $\beta$-tubulin.

\section{Statistical analysis}

All statistical analyses were performed with SPSS version 13.0 (Statistical Package for the Social Science, SPSS Inc., Chicago, IL). Results are expressed as means \pm SD or SE. The analysis of Student's $t$-test or one-way ANOVA was used to identify significant differences between different groups. Spearman correlation was used to determine the main factor(s) that influence serum RBP4. All $P$-values are two-tailed and a $P$-value less than 0.05 is considered statistically significant.

\section{Results}

Pioglitazone reduces RBP4 expression, glucose and lipid metabolism in obese rats

We first explored whether pioglitazone improves glucose and lipid metabolism in HFD-fed obese rats. Rats fed a HFD showed a marked increase in body weight, fasting blood glucose, insulin and plasma lipid profiles including total cholesterol, triglyceride and LDL-C, and a decrease in HDL-C as compared to the normal diet fed control animals (Table 1). These metabolic changes were restored to normal levels by a 4-week pioglitazone treatment. Compared to HFD-UT group, the HFD-PT group elicited a significantly $(P<0.05)$ lower level of fasting blood glucose and insulin, triglyceride and LDL-C, and a significant higher level of HDL-C (Table 1). The expression level of ALT and GGT that was moderately elevated in the HFD-UT group was significantly $(P<0.05)$ attenuated by pioglitazone treatment (Table 1$)$. Importantly, increase of serum RBP4 level in the HFD-UT group was abolished by poglitazone treatment in the HFD-PT group (Table 1).

Table 1. Effects of pioglitazone on body weight and metabolic values. The below parameters were analyzed with the blood from control (CON), HFD un-treated, and HFD pioglitazone-treated rats. HDL-C: high density lipoprotein cholesterol, LDL-C: low density lipoprotein cholesterol, ALT: alanine aminotransferase, RBP4: retinol binding protein 4, AST: aspartate-aminotransferase, and GGT: $\gamma$-glutamyl-transpeptidase. Values are mean $\pm \mathrm{SE}$, and differences between groups were analyzed by t-test. a: compared with control group, and b: compared with HFD un-treated group. $\dagger: P<0.05, \neq: P<0.01$

\begin{tabular}{lccc}
\hline Parameters & CON $(n=8)$ & Un-treated $(n=8)$ & $\begin{array}{c}\text { HFD } \\
\text { Pioglitazone-treated }(n=8)\end{array}$ \\
\hline Weight $(\mathrm{g})$ & $430 \pm 32.6$ & $500 \pm 10.9 \mathrm{a} \neq$ & $480 \pm 17.1 \mathrm{~b} \dagger$ \\
Fasting blood glucose $(\mathrm{mM})$ & $4.10 \pm 0.19$ & $5.45 \pm 0.16 \mathrm{a} \neq$ & $4.56 \pm 0.35 \mathrm{~b} \dagger$ \\
Fasting insulin $(\mathrm{ng} / \mathrm{ml})$ & $0.35 \pm 0.16$ & $0.68 \pm 0.09 \mathrm{a} \neq$ & $0.45 \pm 0.17 \mathrm{~b} \neq$ \\
Triglyceride $(\mathrm{mM})$ & $0.63 \pm 0.15$ & $0.98 \pm 0.31 \mathrm{a} \neq$ & $0.72 \pm 0.10 \mathrm{~b} \dagger$ \\
Total cholesterol $(\mathrm{mM})$ & $1.16 \pm 0.11$ & $2.20 \pm 0.27 \mathrm{a} \neq$ & $1.29 \pm 0.29 \mathrm{~b} \dagger$ \\
HDL-C $(\mathrm{mM})$ & $0.69 \pm 0.17$ & $0.51 \pm 0.20 \mathrm{a} \neq$ & $0.60 \pm 0.26$ \\
LDL-C $(\mathrm{mM})$ & $0.16 \pm 0.08$ & $0.31 \pm 0.12 \mathrm{a} \neq$ & $0.14 \pm 0.10 \mathrm{~b} \neq$ \\
ALT $(\mathrm{u} / \mathrm{l})$ & $43.60 \pm 7.60$ & $57.40 \pm 11.30 \mathrm{a} \dagger$ & $46.10 \pm 6.50 \mathrm{~b} \dagger$ \\
AST $(\mathrm{u} / \mathrm{l})$ & $206 \pm 32$ & $214 \pm 55$ & $196 \pm 20$ \\
GGT $(\mathrm{u} / \mathrm{l})$ & $2.00 \pm 0.00$ & $3.44 \pm 3.04 \mathrm{a} \dagger$ & $1.44 \pm 0.52 \mathrm{~b} \dagger$ \\
Serum RBP4 $(\mu \mathrm{g} / \mathrm{ml})$ & $31.2 \pm 8.2$ & $78.3 \pm 14.6 \mathrm{a} \neq$ & $30.3 \pm 8.0 \mathrm{~b} \neq$ \\
\hline
\end{tabular}


Fig. 1. Pioglitazone improved insulin sensitivity in obese rats. The values shown are (A) blood glucose and (B) serum insulin during oral glucose tolerance test (OGTT), and (C) blood glucose levels during insulin tolerance test (ITT). Data are presented the mean \pm SD $(n=8)$. ${ }^{*} P<0.05$, and ${ }^{* *} P<0.01$.

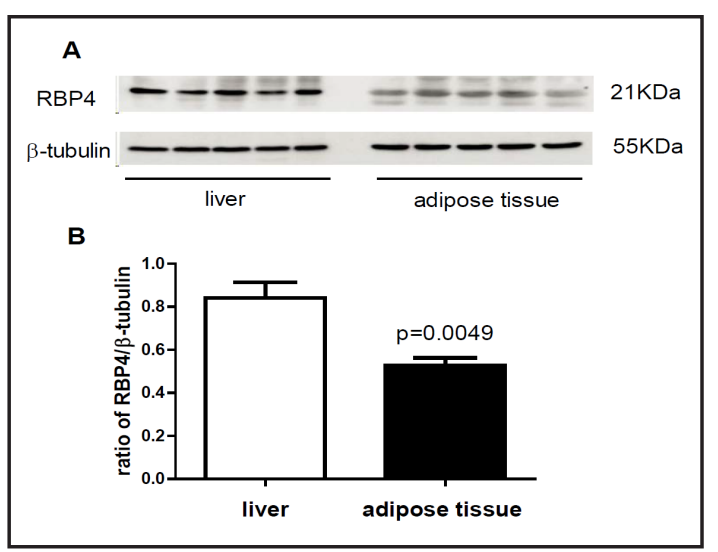

Fig. 2. The expression of RBP4 in the liver and adipose tissue of normal rats. Western blotting analysis shows that RBP4 expression in the liver was significantly $(P<0.05)$ higher than that in the adipose tissue.

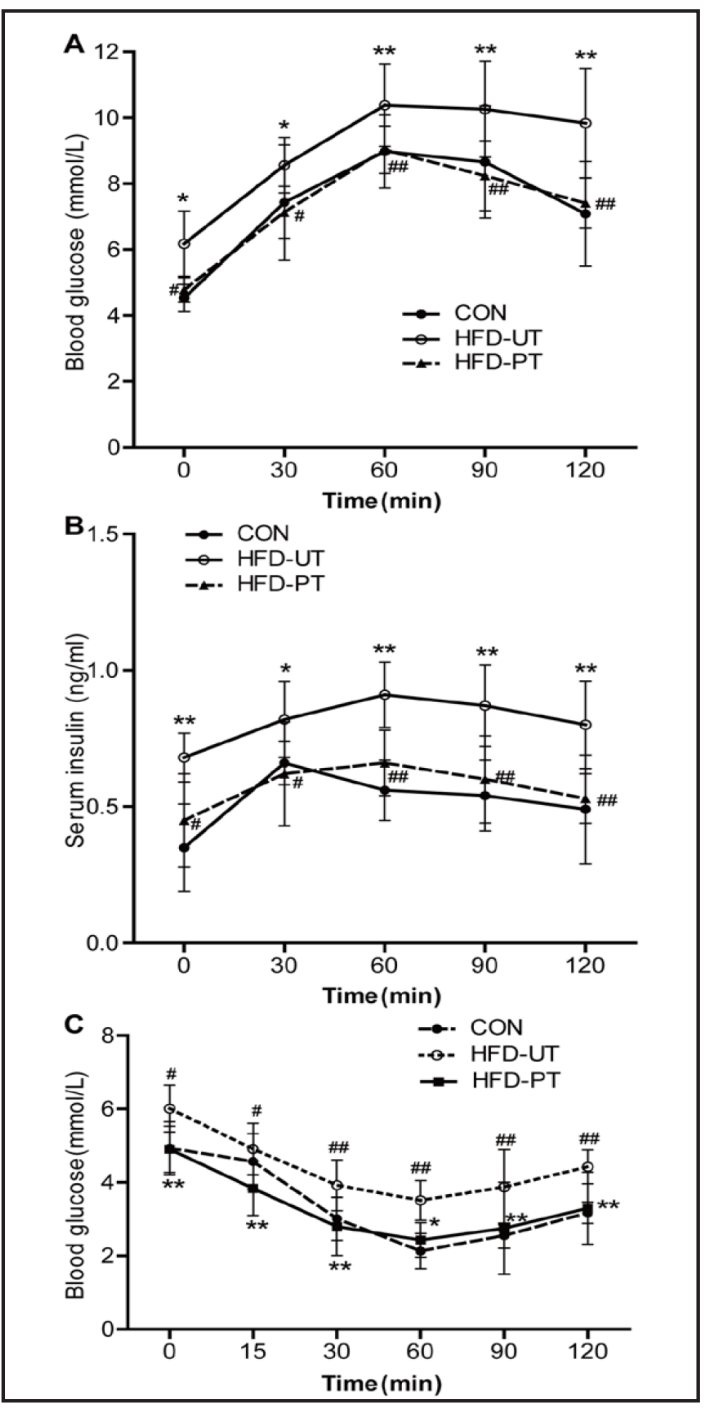

Pioglitazone treatment improves insulin sensitivity in obese rats

We next examined whether pioglitazone improves insulin sensitivity in obese rats. Fasting insulin, $\mathrm{AUC}_{\mathrm{BG}}, \mathrm{AUC}_{\mathrm{INS}}$ and $\mathrm{AUC}_{\mathrm{ITT}}$ were measured to determine insulin sensitivity. All of the above indicators were higher in the HFD-UT group than in the control group (37.22 \pm 4.71 vs. $29.45 \pm 2.37 ; 3.34 \pm 1.71$ vs. $2.18 \pm 1.07 ; 21.45 \pm 2.07$ vs. $15.39 \pm 1.04$; respectively, $P<0.01)$. These results suggested that insulin sensitivity was impaired in the HFD-UT rats. In contrast, fasting insulin levels $(0.45 \pm 0.17 \mathrm{ng} / \mathrm{ml}), A_{\mathrm{BG}}\left(30.52 \pm 2.42 \mathrm{mmol} \cdot \mathrm{min} \cdot \mathrm{L}^{-1}\right)$, $\mathrm{AUC}_{\mathrm{INS}}\left(2.37 \pm 1.12 \mathrm{ng} \cdot \mathrm{min} \cdot \mathrm{ml}^{-1}\right)$, and $\mathrm{AUC}_{\mathrm{ITT}}\left(15.95 \pm 2.14 \mathrm{mmol} \cdot \mathrm{min} \cdot \mathrm{L}^{-1}\right)$ were all decreased in the HFD-PT group (Fig. 1).

Pioglitazone attenuates RBP4 expression in the adipose tissue of obese rats

Previous reports have demonstrated that RBP4 was primarily expressed in the liver and adipose tissue [16]. We herein assessed the expression of RBP4 in the liver and epididymis adipose of normal rats and showed that RBP4 expression was higher in the liver than in the adipose tissue (Fig. 2). Attenuation of serum RBP4 level (Table 1) by pioglitazone suggested that RBP4 expression might be down-regulated in the liver and/or adipose tissues. To determine the relative contribution of adipose tissue and liver to the serum RBP4 in response to pioglitazone treatment, we evaluated RBP4 expression at both the mRNA and protein levels in the adipose tissue and liver. The result showed that, compared to the control group, the HFD-UT group showed a significant $(P<0.01)$ increase in both RBP4 mRNA and protein 


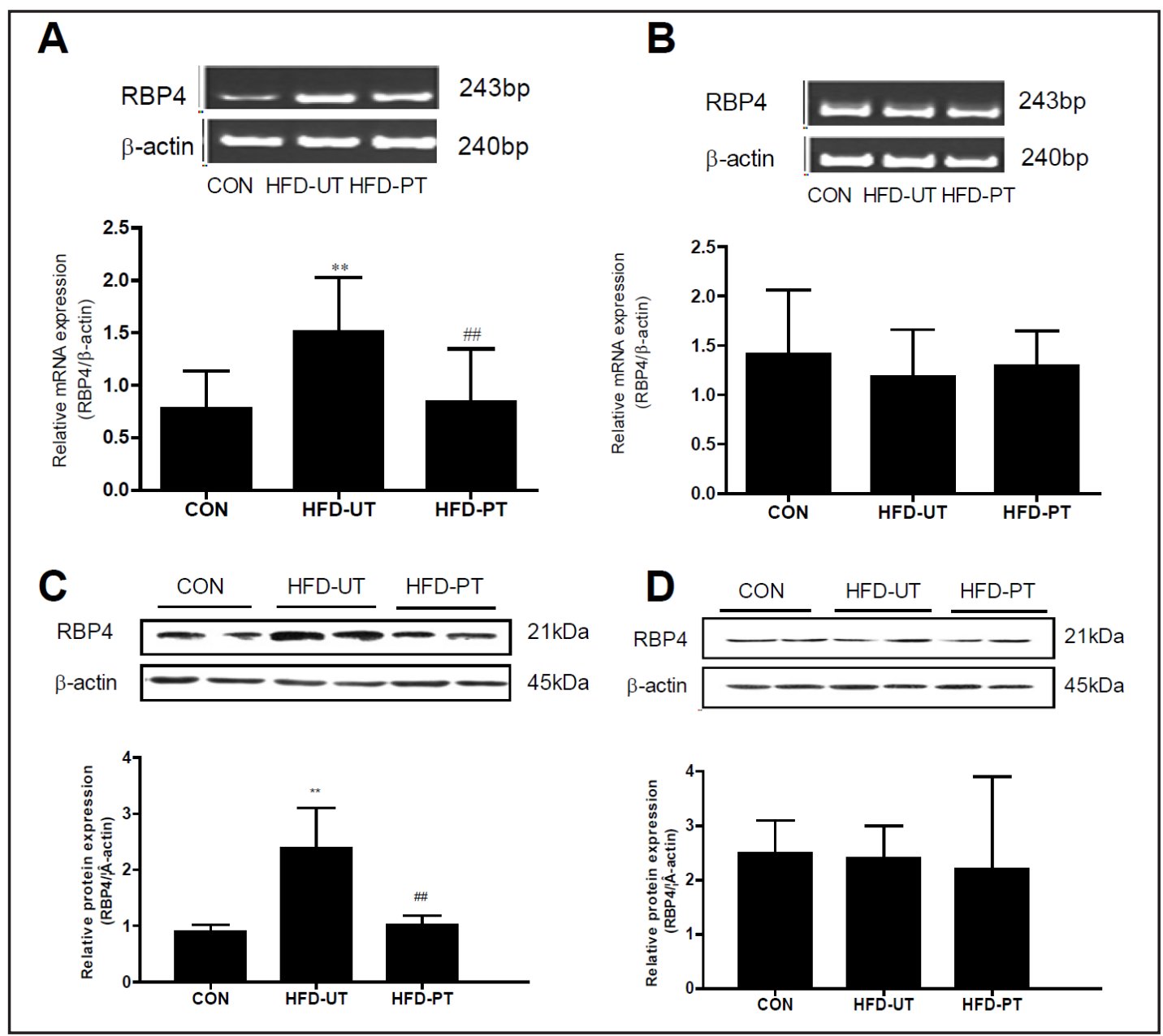

Fig. 3. Pioglitazone attenuates obesity-associated increase of RBP4 expression in the rats. The expression of RBP4 mRNA (A and B) and protein (C and D) was examined by RT-PCR and Western blotting, respectively, in the adipose tissue (A and C) and liver (B and D) of control (CON), HFD un-treated (HFD-UT) and HFD pioglitazone-treated (HFD-PT) rats. The relative expression of RBP4 mRNA and protein was normalized to the internal control $\beta$-actin, and data are expressed as mean $\pm \mathrm{SE}(n=8){ }^{* *} P<0.01$, compared with CON; and \#\# $P<0.01$, compared with HFD-UT.

expression by $93.9 \%$ and $168 \%$, respectively, in the epididymal adipose tissue (Fig. 3A and 3C). Moreover, the increased expression of RBP4 mRNA and protein were dramatically reduced by pioglitazone treatment in the HFD-PT group (Fig. 3A and 3C). In contrast, there was no significant difference in RBP4 expression at the mRNA or protein level in the liver among the control, HFD-UT, and HFD-PT groups (Fig. 3B and 3D). The difference of RBP4 expression in adipose tissue and liver of HFD-PT animals might be due to increase of PPAR $\gamma$ expression in adipose tissue, but not liver, in response to high fat feeding (data not shown). These findings suggest that changes of RBP4 gene expression in the adipose tissue, but not in the liver, might be responsible for fluctuation of serum RBP4 levels in response to HFD and pioglitazone treatment.

RBP4 expression in the adipose tissue positively correlates with insulin resistance

Serum RBP4 levels were positively correlated with $\mathrm{AUC}_{\mathrm{BG}}(\mathrm{R}=0.468, P<0.05)$ and $\mathrm{AUC}_{\mathrm{ITT}}$ $(\mathrm{R}=0.636, P<0.01$ ) (Table 2). Serum RBP4 levels were also significantly and positively correlated with RBP4 mRNA $(\mathrm{R}=0.594, P<0.01)$ and protein $(\mathrm{R}=0.648, P<0.01)$ levels in epididymal adipose tissue (Fig. 4A and 4B). By contrast, serum RBP4 was not correlated 
Fig. 4. Correlation of serum RBP4 with RBP4 expression in the adipose tissue and liver. Based on Spearman correlation analysis, serum RBP4 is significantly correlated with RBP4 expression at both mRNA (A, $r=0.594$, $P<0.01$ ) and protein (C, $r=0.648, P<0.01$ ) levels in the adipose tissues, but not with RBP4 expression at either mRNA (B, $r=0.12, P=0.57$ ) or protein (D, $r=0.186, P=$ 0.358 ) level in the liver.

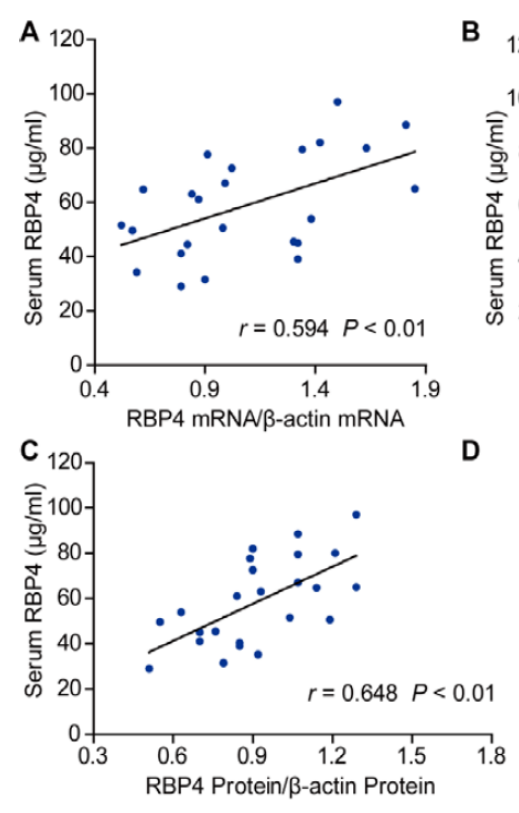

B

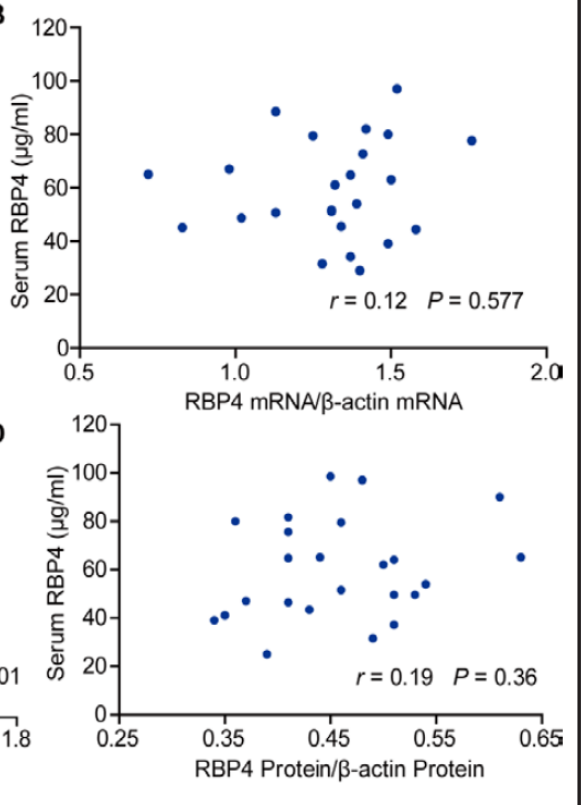

Table 2. Correlation of RBP4 levels with metabolic values. Spearman correlation analysis was conducted in the data pooled from all of the rats. $\neq: P<0.01, \uparrow: P<0.05$. NS, not significant correlation

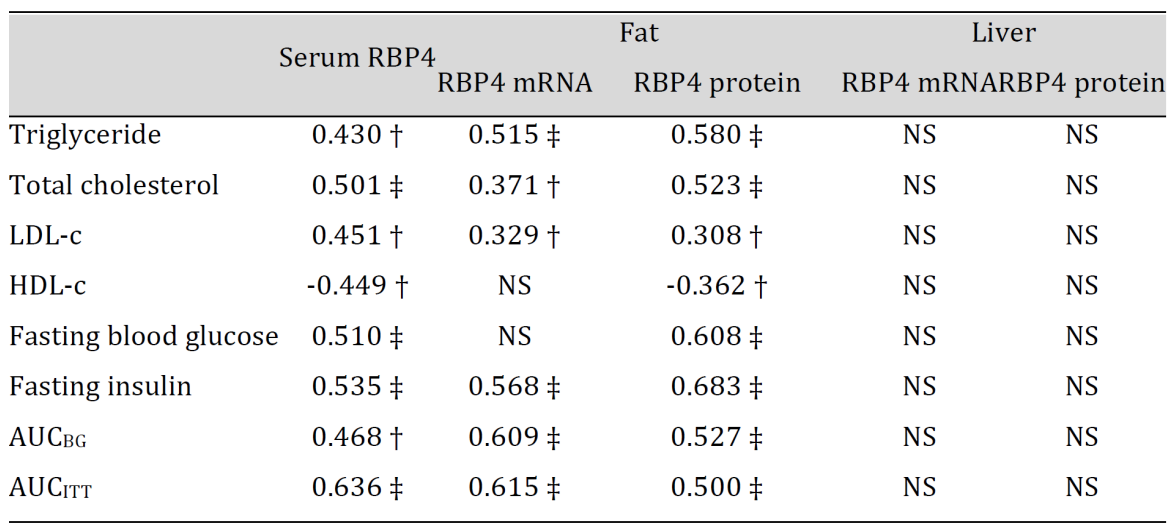

with RBP4 expression at either mRNA $(\mathrm{R}=0.12, P=0.57)$ or protein $(\mathrm{R}=0.186, P=0.358)$ level in the liver (Fig. 4C and 4D). Additionally, both the mRNA and protein expression of $\mathrm{RBP} 4$ in the adipose tissue were positively correlated with $\mathrm{AUC}_{\mathrm{BG}}(\mathrm{R}=0.609$ and $\mathrm{R}=0.527$, respectively, both $P<0.01$ ) and $\mathrm{AUC}_{\mathrm{ITT}}(\mathrm{R}=0.615$ and $\mathrm{R}=0.500$, respectively, both $P<0.01$ ). However, there was no significant correlation between RBP4 expression in the liver and insulin resistance relevant parameters (Table 2). Moreover, we found that serum RBP4 and RBP4 expression in the adipose tissue but not in the liver were correlated with the metabolic data such as triglyceride, total cholesterol and LDL-C (Table 2). Taken together, these data indicate that pioglitazone ameliorates insulin resistance by down-regulating the expression of RBP4 in adipose tissue of obese rats.

Pioglitazone down-regulates RBP4 expression in cultured 3T3-L1 adipocytes

We further confirmed whether the inhibitory effect of pioglitazone on RBP4 expression was reproducible in cultured adipocytes using hepatocytes as a control. Cultured 3T3-L1 adipocytes and HepG2 hepatocytes were first exposed to $300 \mu \mathrm{M}$ palmitate for $24 \mathrm{~h}$, which was followed by a combined treatment with pioglitazone at the concentration of 5,10 , or 


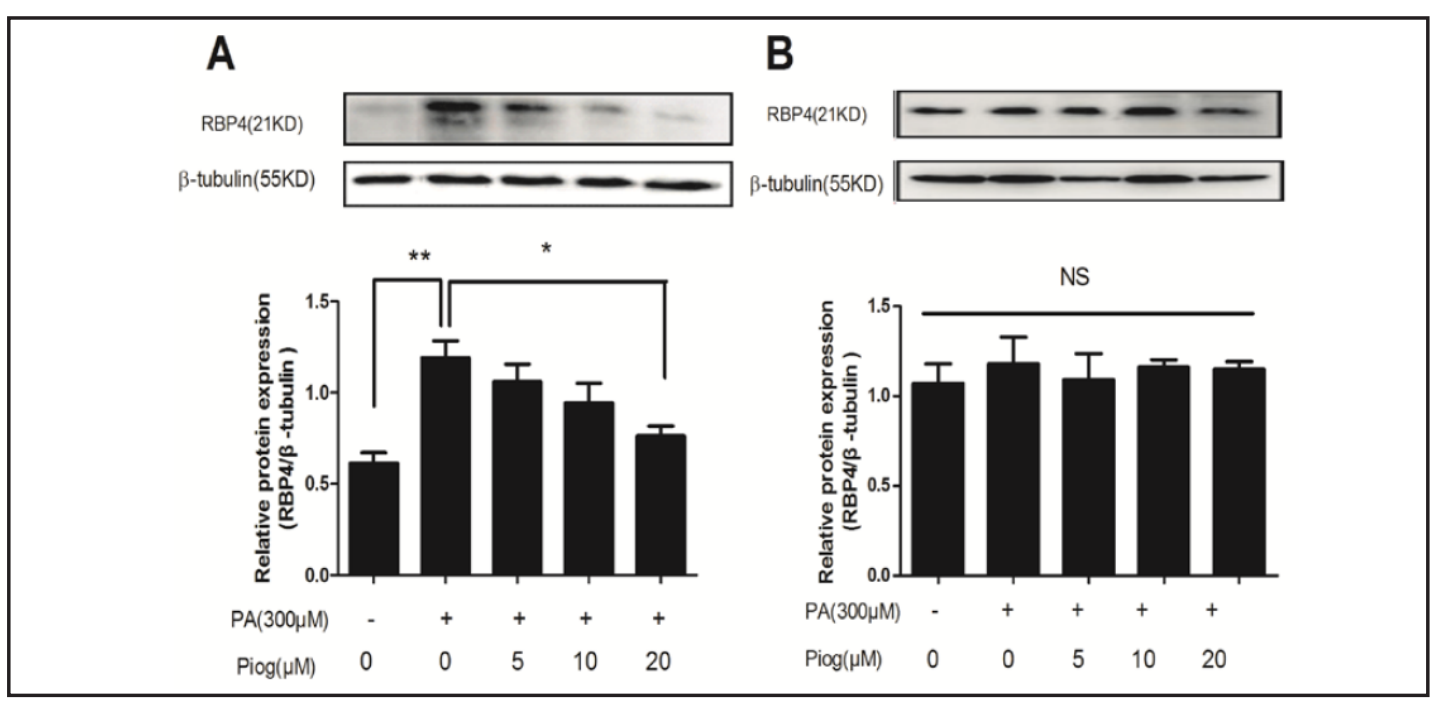

Fig. 5. Pioglitazone attenuates RBP4 expression in 3T3-L1 adipocytes but not HepG2 hepatocytes. Both 3T3-L1 adipocytes (A) and HepG2 hepatocytes (B) were treated with $300 \mathrm{M}$ palmitic acid (PA) for 24h,with or without pioglitazone (Piog) at the concentration of 5, 10, or $20 \mu \mathrm{M}$. The relative expression of RBP4 protein was normalized to the internal control $\beta$-tubulin and data are expressed as mean $\pm \mathrm{SE}(n=4) .{ }^{* *} P<0.01$, ${ }^{*} P<0.05$, and NS, not significant.

$20 \mu \mathrm{M}$. It is important to note that cell viability test showed no cytotoxicity to either 3T3L1 or HepG2 cells with $300 \mu \mathrm{M}$ palmitate (data not shown). Palmitate treatment increased protein expression of RBP4 in 3T3-L1 adipocytes by 100\% (Fig. 5A). Consistent with our findings in in vivo adipose tissue, pioglitazone at $20 \mu \mathrm{M}$ suppressed RBP4 protein level by approximately $44 \%$ in 3T3-L1 adipocytes, whereas pioglitazone at lower concentrations did not cause a significant change despite of a slight decrease. On the other hand, neither palmitate nor pioglitazone altered the expression of RBP4 in HepG2 cells (Fig. 5B). These results demonstrate that pioglitzone specifically regulates RBP4 expression in the adipocytes, but not in the hepatocytes.

\section{Discussion}

With an increasing prevalence of obesity, there is a trend toward a higher incidence of insulin resistance, hyperlipidemia, cardiovascular diseases, type 2 diabetes and fatty liver. Adipocyte-derived cytokines have been proposed as diagnostic markers and therapeutic targets for obesity-linked insulin resistance, diabetes, and fatty liver [17]. Many adipokines are implicated directly in the pathologies associated with obesity, particularly the metabolic syndromes [18]. RBP4 is a compact and globular protein that was first identified as a retinol carrier, and is mainly synthesized and secreted by the liver [19]. Recently, an increasing body of evidence has identified RBP4 as an adipokine and elevated RBP4 expression is closely related to insulin resistance and type 2 diabetes [20]. Ost et al. showed that RBP4 is likely released from the adipocytes and acts locally to inhibit phosphorylation of IRS1 at serine 307, thereby disrupting insulin-mediated nutrient sensing [21]. In the present study, we showed that serum RBP4 level in rats is enhanced by high fat diet and that RBP4 is primarily synthesized in the liver and secondly in the adipose tissue. We further showed that pioglitazone treatment attenuated circulating RBP4 abundance in obese rats. Pioglitazone is a selective and potent ligand for the nuclear transcription factor PPAR $\gamma$. It has been widely used to ameliorate hyperglycemia and to improve insulin sensitivity in type 2 diabetic patients. The role of pioglitazone in the treatment of obesity and insulin resistance 
insulin is through the control of glucose and lipid metabolism in the liver, adipose tissue and muscle by modulating the transcription of -sensitive genes [22]. Our finding of the inhibitory effect of pioglitazone on serum RBP4 expression is consistent with a previous report that pioglitazone improves insulin resistance through decreasing the level of serum RBP4 [23].

The primary goal of this study was to understand the main source of RBP4 secretion that contributes to the change of serum RBP4 level under obese/diabetic and therapeutic conditions. We demonstrated for the first time that high fat diet-induced increase and pioglitazone-mediated decrease in the abundance of circulating RBP4 are primarily due to change of RBP4 expression in the adipose tissue. These findings are consistent with our previous report that fenofibrate, a PPAR $\alpha$ agonist, suppresses serum RBP4 level also by down-regulating RBP4 expression in the adipose tissue [24]. However, Yao-Borengsser et al. showed that pioglitazone increased RBP4 gene expression in the white adipose tissue of human patients [25]. This discrepancy may be due to the analysis of RBP4 expression in different adipose tissues: visceral adipose tissue in this study while subcutaneous adipose tissue in the human patients' study. Surprisingly, we did not find a change of RBP4 expression in the liver in response to either high fat diet or pioglitazone treatment, although RBP4 is abundantly expressed in the liver and secreted into the circulation in a 1:1:1 complex with retinol (holo-RBP4) and transthyretin [26]. This finding from the in vivo tissues was confirmed by the in vitro cell culture experiment wherein pioglitazone inhibited RBP4 expression only in adipocytes, but not hepatocytes. Our observation may help to explain a previous finding by Bahr et al. that hepatic RBP4 expression is not associated with insulin resistance [27]. However, it remains unknown why RBP4 expression is differentially regulated by pioglitazone in the adipose tissue and liver. One explanation may be related to the expression of PPAR $\gamma$. PPAR $\gamma$, the downstream effector of pioglitazone in RBP4 regulation, is more abundantly expressed in the adipose tissue than in the liver. In fact, previous studies have shown that PPAR $\gamma$ is predominantly expressed in adipose tissues and immune system and, to a lesser extent, in the liver [28].

In conclusion, we showed that serum RBP4 was increased in obese rats and pioglitazone treatment suppressed the abundance of circulating RBP4. RBP4 expression was higher in the liver and relatively lower in the adipose tissue; however, only RBP4 in the adipose tissue was subjected to regulation in obese condition and by the PPAR $\gamma$ activator, pioglitazone. These findings suggest that targeting RBP4 expression in the adipose tissue is a potential strategy in the treatment of insulin resistance and type 2 diabetes.

\section{Abbreviations}

RBP4 (retinol binding protein 4); PPAR (peroxisome proliferator-activated receptor); HDL-C (high-density lipoprotein cholesterol); LDL-C (low-density lipoprotein cholesterol); ALT (alanine aminotransferase); $\mathrm{AUC}_{\mathrm{BG}}$ (areas under curves of glucose); $\mathrm{AUC}_{\mathrm{INS}}$ (areas under curves of insulin); $\mathrm{AUC}_{\mathrm{ITT}}$ (areas under curves of glucose in insulin tolerance test); AST (alanine aminotransferase); GGT ( $\gamma$-glutamyl-transpeptidase).

\section{Acknowledgment}

This work was funded by Key Disciplines Group Construction Project of Pudong Health Bureau of Shanghai (PWZxq2014-07) to Li Wei, Foundation of Shanghai Key Laboratory of Diabetes Mellitus (08DZ2230200) to Weiping Jia.

\section{Disclosure Statement}

There are no conflicts of interest for the study. 
Zhu et al.: Pioglitazone Down-Regulates RBP4

\section{References}

1 Kanaya AM, Harris T, Goodpaster BH, Tylavsky F, Cummings SR; Health, Aging, and Body Composition (ABC) Study: Adipocytokines attenuate the association between visceral adipose tissue and diabetes in older adults. Diabetes Care 2004;27:1375-1380.

2 Zoico E, Di Francesco V, Mazzali G, Vettor R, Fantin F, Bissoli L, Guariento S, Bosello O, Zamboni M: Adipocytokines, fat distribution, and insulin resistance in elderly men and women. J Gerontol A Biol Sci Med Sci 2004;59:M935- M939.

-3 Graham TE, Yang Q Blüher M, Hammarstedt A, Ciaraldi TP, Henry RR, Wason CJ, Oberbach A, Jansson PA, Smith U, Kahn BB: Retinol-binding protein 4 and insulin resistance in lean, obese, and diabetic subjects. $\mathrm{N}$ Engl J Med 2006;354:2552-2563.

-4 Balagopal P, Graham TE, Kahn BB, Altomare A, Funanage V, George D: Reduction of elevated serum retinol binding protein in obese children by lifestyle intervention: association with subclinical inflammation. J Clin Endocrinol Metab 2007;92:1971-1974.

-5 Takebayashi K, Suetsugu M, Wakabayashi S, Aso Y, Inukai T: Retinol binding protein-4 levels and clinical features of type 2 diabetes patients. J Clin Endocrinol Metab 2008;92:2712-2719.

6 Gavi S, Stuart LM, Kelly P, Melendez MM, Mynarcik DC, Gelato MC, McNurlan MA: Retinol-binding protein 4 is associated with insulin resistance and body fat distribution in nonobese subjects without type 2 diabetes. J Clin Endocrinol Metab 2007;92:1886-1890.

7 Mcilroy GD, Delibegovic M, Owen C, Stoney PN, Shearer KD, McCaffery PJ, Mody N: Fenretinide treatment prevents diet-induced obesity in association with major alterations in retinoid homeostatic gene expression in adipose, liver, and hypothalamus. Diabetes 2013;62:825-836.

8 Koh IU, Jun HS, Choi JS , Lim JH, Kim WH, Yoon JB, Song J: Fenretinide ameliorates insulin resistance and fatty liver in obese mice. Biol Pharm Bull 2012;35:369-375.

9 Ahmadian M, Suh JM, Hah N, Liddle C, Atkins AR, Downes M, Evans RM: PPAR $\gamma$ signaling and metabolism: the good, the bad and the future. Nat Med 2013;19:557-566.

10 Hammarstedt A, Andersson CX, Rotter Sopasakis V, Smith U: The effect of PPAR $\gamma$ ligands on the adipose tissue in insulin resistance. Prostaglandins Leukot Essent Fatty Acids 2005;73:65-75.

-11 Bell LN, Wang J, Muralidharan S, Chalasani S, Fullenkamp AM, Wilson LA, Sanyal AJ, Kowdley KV, Neuschwander-Tetri BA, Brunt EM, McCullough AJ, Bass NM, Diehl AM, Unalp-Arida A, Chalasani N; Nonalcoholic Steatohepatitis Clinical Research Network: Relationship between adipose tissue insulin resistance and liver histology in nonalcoholic steatohepatitis: A pioglitazone versus vitamin E versus placebo for the treatment of nondiabetic patients with nonalcoholic steatohepatitis trial follow-up study. Hepatology 2012;56:1311-1318.

12 Yang Q Graham TE, Mody N, Preitner F, Peroni OD, Zabolotny JM, Kotani K, Quadro L, Kahn BB: Serum retinol binding protein 4 contributes to insulin resistance in obesity and type 2 diabetes. Nature 2005;436:356-362.

13 Lin KD, Chang YH, Wang CL, Yang YH, Hsiao PJ, Li TH, Shin SJ: Thiazolidinedione addition reduces the serum retinol-binding protein 4 in type 2 diabetic patients treated with metformin and sulfonylurea. Transl Res 2008;151:309-314.

14 Teranishi T, Ohara T, Maeda K, Zenibayashi M, Kouyama K, Hirota Y, Kawamitsu H, Fujii M, Sugimura K, Kasuga M: Effects of pioglitazone and metformin on intracellular lipid content in liver and skeletal muscle of individuals with type 2 diabetes mellitus. Metabolism 2007;56:1418-1424.

15 De Souza CJ, Eckhardt M, Gagen K, Dong M, Chen W, Laurent D, Burkey BF: Effects of pioglitazone on adipose tissue remodeling within the setting of obesity and insulin resistance. Diabetes 2001;50:18631871.

-16 Esteve E, Ricart W, Fernández-Real JM: Adipocytokines and insulin resistance: the possible role of lipocalin-2, retinol binding protein-4, and adiponectin. Diabetes Care 2009;32:S362-S367.

17 Rabe K, Lehrke M, Parhofer KG, Broedl UC: Adipokines and Insulin Resistance. Mol Med 2008;14:741-751.

18 Galic S, Oakhill JS, Steinberg GR: Adipose tissue as an endocrineorgan. Mol Cell Endocrinol 2010;316:129139.

19 Koh IU, Jun HS, Choi JS, Lim JH, Kim WH, Yoon JB, Song J: Fenretinide ameliorates insulin resistance and fatty liver in obese mice. Biol Pharm Bull 2012;35:369-375. 


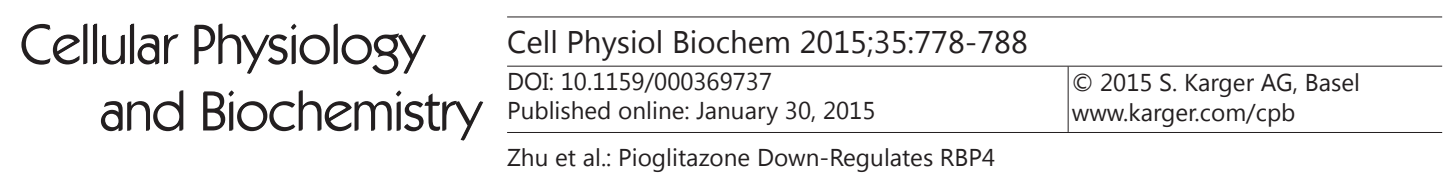

20 Kim YL, Kim TK, Cheong ES, Shin DG, Choi GS, Jung J, Han KA, Min KW: Relation of absolute or relative adiposity to insulin resistance, retinol binding protein-4, leptin, and adiponectin in type 2 diabetes. Diabetes Metab J 2012;36:415-421.

-21 Ost A, Danielsson A, Lidén M, Eriksson U, Nystrom FH, Strålfors P: Retinol-binding protein-4 attenuates insulin-induced phosphorylation of IRS1 and ERK1/2 in primary human adipocytes. FASEB J 2007;21:3696-3704.

-22 Hsiao G, Chapman J, Ofrecio JM, Wilkes J, Resnik JL, Thapar D, Subramaniam S, Sears DD: Multi-tissue, selective PPAR $\gamma$ modulation of insulin sensitivity and metabolic pathways in obese rats. Am J Physiol Endocrinol Metab 2011;300:E164-E174.

23 Haider DG, Schindler K, Mittermayer F, Müller M, Nowotny P, Rieger A, Luger A, Ludvik B, Wolzt M: Effect of rosiglitazone on visfatin and retinol-binding protein-4 plasma concentrations in HIV-positive patients. Clin Pharmacol Ther 2007;81:580-585.

24 Wu H, Wei L, Bao Y, Lu J, Huang P, Liu Y, Jia W, Xiang K: Fenofibrate reduces serum retinol-binding protein-4 by suppressing its expression in adipose tissue. Am J Physiol Endocrinol Metab 2009;296:E628-E634.

25 Yao-Borengasser A, Varma V, Bodles AM, Rasouli N, Phanavanh B, Lee MJ, Starks T, Kern LM, Spencer HJ 3rd, Rashidi AA, McGehee RE Jr, Fried SK, Kern PA: Retinol binding protein 4 expression in humans: relationship to insulin resistance, inflammation, and response to pioglitazone. J Clin Endocrinol Metab 2007;92:2590-2597.

-26 Schina M, Koskinas J, Tiniakos D, Hadziyannis E, Savvas S, Karamanos B, Manesis E, Archimandritis A: Circulating and liver tissue levels of retinol-binding protein-4 in non-alcoholic fatty liver disease. Hepatol Res 2009;39:972-978.

27 Bahr MJ, Boeker KH, Manns MP, Tietge UJ: Decreased hepatic RBP4 secretion is correlated with reduced hepatic glucose production but is not associated with insulin resistance in patients with liver cirrhosis. Clin Endocrinol 2009;70:60-65.

-28 Braissant O, Foufelle F, Scotto C, Dauça M, Wahli W: Differential expression of peroxisome proliferatoractivated receptors (PPARs): tissue distribution of PPAR-alpha, -beta, and -gamma in the adult rat. Endocrinology 1996;137:354-366. 